\title{
PENGARUH TEKNIK MASSASE EFFLEURAGE TERHADAP TINGKAT NYERI PADA IBU BERSALIN KALA I FASE AKTIF
}

\author{
Eline Charla Sabatina Bingan ${ }^{1}$ \\ ${ }^{1}$ Poltekkes Kesehatan Palangka Raya
}

\begin{abstract}
A mother who faces childbirth tends to be afraid especially with primigravida. Because that pain must be alleviated effectively because pain accompanied by stress reactions have harmful effects on the mother and fetus. One way to overcome the problem of pain during labor is a Massase Effleurage. Abdominal massage or massage (Effleurage) is a form of skin stimulation used during labor that has a relaxing effect. This study aims to analyze the result of the Massase Effleurage technique reducing the paint level in first phase favorable mothers on BPM in the environmental area of Panarung Public Health Center at Palangka Raya. This study uses a Pre-Experimental research method with One Group PretestPosttest Design with samples in this study are maternity mothers who are facing the first stage of the latent phase that is included in the inclusion criteria. Bivariate analysis results using the Wilcoxon signed rank test at alpha 0.05 obtained $P$ value $0,000(p<0.05)$ which there is a significant influence between pain previous massase and after massase, in other words if done Massase Effleurage can reduce pain. So that the results that there an impact the Massase Effleurage technique in pain the first stage of latent phase.
\end{abstract}

Keywords : Maternity Mother, Massage Effleurage, Labor Pain 


\section{PENDAHULUAN}

Persalinan normal adalah suatu keadaan yang menegangkan bagi kebanyakan perempuan. Bagi ibu yang mengalami proses persalinan cenderung merasa khawatir terutama jika ibu tersebut belum pernah melahirkan. Ketika kekhawatiran itu dialami maka secara otomatis otak akan mengatur dan menyiapkan tubuh untuk merasakan sakit sehingga sakit saat persalinan akan lebih terasa, oleh karena itu nyeri harus diredakan dengan efektif karena nyeri disertai dengan reaksi stres memiliki dampak resiko baik pada ibu dan calon bayi (Wahyuningsih, 2009).

Rasa sakit pada saat melahirkan muncul akibat respon fisik dan psikis, juga dapat menimbulkan hiperventilasi, sehingga kebutuhan oksigen meningkat, kenaikan tekanan darah, dan berkurangnya motilitas usus serta vesika urinaria. Sedangkan bila rasa sakit persalinan tidak dapat diatasi maka akan membuat terjadinya partus lama (Bobak, 2012).

Menurut data yang diperoleh dari WHO, yaitu sebanyak 99 persen penyebab kematian pada ibu disebabkan karena kasus persalinan yang terjadi di negara-negara berkembang, Indonesia masih menempati urutan kedua tertinggi dinegara ASEAN dimana salah satu penyebab keempat terbesar adalah partus lama.
Tindakan yang dapat dilakukan utuk mengatasi nyeri pada saat persalinan dapat menggunakan cara nonfarmakologi. Salah satu cara untuk mengatasi permasalahan nyeri selama persalinan adalah teknik pijat, yang mulai dikembangkan dan dapat digunakan baik oleh bidan maupun penolong persalinan adalah pijat Effleurage. Massase atau pijatan pada bagian perut (Effleurage) merupakan wujud rangsangan pada kulit yang digunakan selama proses persalinan yang menyebabkan dampak rileks bagi tubuh. Teknik Massase Effleurage dilakukan dengan memakai telapak jari tangan dengan bentuk arah melingkar pada perut,pinggang atau paha. Massase Effleurage pada bagian perut merupakan salah satu cara nonfarmakologi yang bisa digunakan dalam metode Lamaze untuk mengurangi rasa sakit pada saat bersalin secara normal.

Pelaksanaan terapi dengan cara nonfarmakologi digunakan untuk mengatasi rasa sakit merupakan cara yang harus dikembangkan oleh setiap bidan atau penolong persalinan. $\mathrm{Di}$ Indonesia teknik massase Effleurage masih belum populer dan masih jarang dilakukan.

Di BPM yang ada diwilayah kerja Puskesmas Panarung Kota Palangka Raya didapatkan datadari bulan Januari 2019 - Oktober 2019 jumlah kunjungan ANC (antenatal care) trimester III berjumlah 132 orang sedangkan jumlah persalinan normal sebanyak 159 orang. 
Sesuai dengan jurnal penelitian yang telah dilakukan bahwa ada pengaruh teknik massase effleuarage terhadap rasa nyeri persalinan, Ibu yang bersalin di BPM pasti merasakan nyeri sedangkan di BPM tersebut belum pernah mengaplikasikan teknik massase effleurage kepada ibu inpartu dan juga belum pernah dilakukan penelitian tentang nyeri persalinan.

\section{METODOLOGI PENELITIAN}

Penelitian ini menggunakan metode penelitian Pre Eksperimental dengan One Group Pretest-Posttest Design. Pengambilan sampel menggunakan teknik Puposive Random Sampling. Sampel pada penelitian ini adalah seluruh ibu bersalin normal kala I fase laten di BPM Puskesmas Panarung yang masuk kriteria inklusi dan akan di wawancara dengan menggunakan lembar kuesioner kemudian diobservasi dan akan dilakukan pengukuran skala nyeri terlebih dahulu sebelum diberi perlakuan, kemudian setelah diberikan perlakuan sampel tersebut akan diobservasi kembali. Data yang telah dikumpulkan kemudian di analisis dengan uji statistik univariat dan bivariat.

\section{HASIL PENELITIAN DAN BAHASAN}

Dari hasil penelitian diBPM kawasan lingkungan Puskesmas Panarung Kota Palangka Raya yang dilakukan sejak bulan Januari- Maret 2020 yaitu untuk menganalisis pengaruh teknik
Massase Effleurage melalui pengurangan ambang sakit pada ibu bersalin kala I fase aktif. Adapun desain penelitian yang digunakan dalam penelitian ini adalah Pre Eksperimental dengan One Group Pretest-Posttest desain dengan sampel sebanyak 26 ibu bersalin normal kala I fase aktif, dengan hasil sebagai berikut

1. Analisis Univariat Tabel 1. Distribusi Frekuensi Intensitas Nyeri Persalinan Sebelum dilakukan Massase Effleurage di BPM Wilayah Kerja Puskesmas Panarung Kota Palangka RayaTahun 2020

\begin{tabular}{ccc}
\hline Tingkat Skala Nyeri & F & $\%$ \\
\hline Skala Nyeri Ringan & 0 & 0 \\
\hline Skala Nyeri Sedang & 24 & 92,3 \\
\hline Skala Nyeri Berat & 2 & 7,7 \\
\hline TOTAL & 26 & 100 \\
\hline
\end{tabular}

Dari dafar tabel diatas dapat kita ketahui bahwa intensitas ambang sakit persalinan sebelum dilakukan masaase effleurage adalah nyeri sedang berjumlah 24 orang $(92,3 \%)$, dan nyeri berat sejumlah 2 orang $(7,7 \%)$.

Tabel 2. Distribusi Frekuensi Tingkat Nyeri Bersalin Setelah dilakukan Massase Effleurage di BPM Wilayah Kerja Puskesmas Panarung Kota Palangka Raya Tahun 2020

\begin{tabular}{cll}
\hline Tingkat Skala Nyeri & \multicolumn{2}{c}{ Total } \\
\hline & $\mathrm{F}$ & $\%$ \\
\hline Skala Nyeri Ringan & 16 & 61,5 \\
\hline Skala Nyeri Sedang & 10 & 48,5 \\
\hline Skala Nyeri Berat & 0 & 0 \\
\hline TOTAL & 26 & 100 \\
\hline
\end{tabular}

Dari tabel diatas menunjukan intensitas skala nyeri responden sesudah diberikan massase effleurage adalah nyeri 
sedang sebanyak 10 orang (48,5\%). Nyeri ringan sebanyak 16 orang (61,5\%).

2. Analisis Bivariat

Hasil analisis bivariat sebelum dan sesudah dilakukan Massase Effleurage di BPM Wilayah Kerja Puskesmas Panarung KotaPalangka Raya Tahun 2020 dengan menggunakan uji statistic wilcoxon dapat dilihat pada tabel dibawah ini.

Tabel 2. Hasil Analisis Data Menggunakan Wilcoxon Sebelum dan Sesudah Dilakukan Massase Effleurage di BPM Wilayah Kerja Puskesmas Panarung Kota Palangka Raya Tahun 2020

\begin{tabular}{clcccc}
\hline No & Intervensi & Mean & SD & $\begin{array}{l}\text { P }(\boldsymbol{P} \\
\text { Value })\end{array}$ & $\mathbf{N}$ \\
& & & & & \\
\hline 1 & $\begin{array}{l}\text { 1.Pre } \\
\end{array}$ & 5,58 & 0,809 & 0,0 & 26 \\
2 & $\begin{array}{l}\text { Massase } \\
\text { Post }\end{array}$ & 3,46 & 0,647 & 00 & \\
& Massase & & & & \\
\hline
\end{tabular}

Pada daftar tabel diatas menunjukan pengaruh reaksi nyeri bersalin kala I fase aktif pada saat awal dilakukan Massase Effleurage dan setelah dilakukanMassase Effleurage. Rerata rasasakit saat awal dilakukan Massase Effleurage yaitu 5,58 dengan simpangan baku 0,809. Sedangkan rasa sakit sesudah Massase Effleurage terlihat nilai rerata sebanyak 3,46 dengan standar deviasi 0,647. Hasil akhirnya diperoleh bahwa nilai $P$ (value) $=0,000$. Berdasarkan Hasil uji statistik pada alpha 0,05 didapatkan $p$ value $0,000 \quad(p<0,05)$ yang berarti ada pengaruh signifikan antara nyeri sebelum massase dengan setelah massase, dengan kata lain jika dilakukan Massase Effleurage dapat menurunkan nyeri. Sehingga dari hasil analisis ini dapat ditarik kesimpulannya ada pengaruh teknik Massase Effleurage terhadap nyeri kala I fase laten.

Pembahasan

Dari hasil penelitian terlihat telah terjadi penurunan tingkat nyeri sebanyak 16 Orang ibu bersalin mengalami nyeri ringan setelah diberi perlakuan Massase Effleurage dengan rata-rata skala nyeri persalinan sebesar $61,5 \%$.

Hasil uji wilcoxon diperoleh nilai pvalue $=0,000$. Dengan demikian nilai pvalue lebih kecil dari 0,05 sehingga dapat disimpulkan terdapat pengaruh Massase Effleurage terhadap penurunan intensitas nyeri persalinan kala I fase aktif. Hasil penelitian ini sejalan dengan hasil penelitian Sri Handayani mengenai pengaruh Massae Effleurage terhadap tingkat nyeri kala I fase aktif di Bantul pada tahun 2016, menunjukkan hasil telaah uji wilcoxon membuktikn bahwa pemberian pijat effleurage pada ibu bersalin kala I fase aktif, berpegaruh signifikan atas derajat nyeri ibu bersalin kala I fase aktif dengan value $=0,000$ $(p<0,05)$.

Effleurage adalah salah satu cara non farmakologis yang dapat digunakan untuk mengurangi rasa sakit selama bersalin yang tertera pada Summary of pain relief measures during labor, dimana pada kala I fase laten (pembukaan 0-3 
$\mathrm{cm}$ ) dan fase aktif (pembukaan 4-7 cm) tindakan yang dapat dikerjakan oleh ibu bersalin adalah dengan melakukan pijat Effleurage. Effleurage merupakan teknik pijatan ringan dengan menggunakan jari tangan, biasanya dilakukan pada bagian perut, selaras dengan pernapasan saat kontraksi.Effleurage dapat dilakukan baik oleh ibu bersalin atau pendamping persalinan sewaktu kontraksi aktif. Hal ini digunakan untuk mengubah perhatian ibu dari rasa sakit saat terjadi kontraksi (Indrayani, 2016).

Dari penelitian yang saya lakukan dengan pemberian teknik massase effleurage pada ibu bersalin kala I dengan intensitas nyeri awal sedang setelah dilakukan atau diberikan teknik Massase Effleurage tersebut mengalami intensitas nyeri ringan sekaligus memberikan pengalaman pengendalian rasa nyeri yang langsung dirasakan oleh ibu bersalin ini benar- benar terjadi.

Pada penelitian menuturkan bahwa ibu yang dipijit selama 20 menit setiap jam sewaktu tahapan bersalin bakal lebih bebas dari rasa sakit, sebab pijat memicu tubuh membebaskan senyawa endorphin yang merupakan pereda sakit alami dan membuat perasaan tenang. Secara statistik terdapat pengaruh yang signifikan antara nilai sig (2-tailed) dengan $0.000<$ 0.05 maka dapat disimpulkan ada pengaruh yang signifikan antara Massase Effleurage atas nyeri kala I fase aktif di Bidan ' $Y$ ' dikawasan lingkungan Puskesmas Panarung Kota Palangka
Raya Tahun 2020. Hasil penelitian ini sependapat dengan hasil penelitian yang dilakukan oleh Herinawati, et al yang berjudul Pengaruh massage effleurage Massage terhadap Nyeri Persalinan Kala I Fase Aktif di Praktik Mandiri Bidan Nuriman Rafida dan Praktik Mandiri Bidan Latifah Kota Jambi Tahun 2019. Penelitian tersebut memberikan hasil didapatkan pengaruh yang signifikan antara Massase Effleurage terhadap penurunan derajat sakit kala I fase aktif dengan $P$ (value) $0.000<0.05$.

\section{KESIMPULAN}

Disimpulkan bahwa ada pengaruh yang signifikan antara Massase Effleurage atas penurunan skala nyeri kala I fase aktif di BPM ' $Y$ ' diwilayah kerja Puskesmas Panarung Kota Palangka Raya Tahun 2020.

\section{SARAN}

Diharapkan penelitian ini dapat menambah wawasan dan ilmu pengetahuan tentang cara menangani nyeri pada persalinan kala I fase laten dengan terapi nonfarmakologi menggunakan teknik massase Effleurage dan bisa diaplikasikan oleh tenaga kesehatan. Hasil penelitian ini dapat dijadikan bahan referensi kepustakaan untuk menambah wawasan dan menunjang penelitian yang akan datangNilai rata-rata tekanan darah sistole sebelum dilakukan intervensi yaitu 145.00 
$\mathrm{mmHg}$ dan setelah dilakukan intervensi tekanan darah sistole menjadi 126.03 $\mathrm{mmHg}$. Sedangkan, untuk nilai rata-rata tekanan darah diastole sebelum dilakukan interve nsi yaitu $91.17 \mathrm{mmHg}$ dan sesudah dilakukan intervensi tekanan darah diastole menjadi $81.03 \mathrm{mmHg}$. Maka terdapat pengaruh yang signifikan antara hipnoterapi terhadap penurunan tekanan darah sistole sebanyak $30 \mathrm{mmHg}$ dan untuk tekanan darah diastole sebanyak $10 \mathrm{mmHg}$.

\section{DAFTAR PUSTAKA}

1. Bobak, Laudermik Jensen. 2012. Buku Ajar keperawatan Maternitas. Jakarta: EGC.

2. Chapman V. 2016. TheMidwife's Labour and Birth Handbook. Oxford: Blackwell Publishing.

3. Danuatmaja, B., Meiliasari, M. 2008. Persalinan Normal Tanpa Rasa Sakit. Jakarta: Puspa Swara.

4. Departemen Kesehatan RI. 2012. Survey Demografikesehatan Indonesia tahun 2012. Jakarta: Depkes RI.

5. Departemen Kesehatan RI. 2012. Survei Kesehatan Rumah Tangga (SKRT), Jakarta: Depkes RI.

6. Esty, Wahyu Gadysa G. 2009. Persepsi lbu Tentang Metode Massage. Jakarta: EGC.

7. Ida Widiawati, Titi Legiati. 2019. Mengenal Nyeri Persalinan Pada Primipara Dan Multipara. Bandung: JURNAL BIMTASVolume: 2, Nomor 1, Dari

https://journal.umtas.ac.id/index.php/b imtas/article/view/340.

8. Herinawati, et al. 2019. Pengaruh Effleurage Massage terhadap Nyeri Persalinan Kala I Fase Aktif di Praktik Mandiri Bidan Nuriman Rafida dan Praktik Mandiri Bidan Latifah Kota Jambi. Jambi, ISSN 1411-8939 (Online). Dari https://www.researchgate.net/publicati on/336898290.
9. Jordy Becker. 2007. Terapi Pijat, Prestasi Pustaka.

10. Laily,Yuliatun. 2008. Penanganan Nyeri persalinan Dengan metode Non Farmakologi. Malang: Bayumedia Publishing.

11. Manurung, Suryani. 2011. Buku Ajar keperawatan maternitas Asuhan Keperawatan Intranatal. Jakarta: Trans Info Media.

12. Mander, R. 2012. Nyeri Persalinan. Jakarta: EGC

13. Manuaba, I. B. G. 2012. Memahami Kesehatan Reproduksi Wanita. Jakarta: EGC

14. Maryuni. 2019. Hubungan Karakteristik Ibu Bersalin dengan Nyeri Persalinan. Jakarta Volume 2, Nomor1-2020. Dari

15. http://stikessitihajar.ac.id/jurnal/index. $\mathrm{php} / \mathrm{jhsp} / \mathrm{article/download/42/35.}$

16. Nila, Qurniash. 2016. Efektivitas Teknik Massage Effleurage Terhadap penurunan Intensitas Nyeri Persalinan Kala I Fase Aktif di Puskesmas Kota Yogyakarta, Yogyakarta, Prodi IImu Kebidanan Magister (S2) Universitas Aisyiyah. (digllib.Unisa Yogya.ac.id).

17. Niarty, S. I. 2018. Pengaruh Effleurage Massage Terhadap Pengurangan Tingkat Nyeri Persalnan Kala I FaseAktif Di BPM Husniyati Dan BPM Yuhana, Palembang. Dari https://repository.poltekkespalembang. ac.id/items/show/195.

18. Perry. G. A, Potter, P. A. 2012. Buku Ajar : Fundamental Keperawatan, Konsep, Proses dan Praktik. Jakarta: EGC.

19. Prawirohardjo, Sarwono. 2012. IImu Kebidanan. Jakarta: Yayasan Bina Pustaka Sarwono Prawirohardjo.

20. Priharyanti Wulandari, Prasita Dwi Nur Hiba. 2015. Pengaruh Massage Effleurage Terhadap Pengurangan Tingkat Nyeri Persalinan Kala I Fase Aktif Pada Primigravida Di Ruang Bougenville RSUD Tugurejo, Semarang, Jurnal Keperawatan Maternitas. Volume 3, No.1. Dari

21. https://jurnal.unimus.ac.id/index.php/J KMat/article/view/4025.

22. Susilawati, Elly. 2017. Efektivitas Pemberian Teknik Massage Effleurage dan Teknik Massage Counterpressure 
Terhadap Rasa Nyeri Persalinan Normal Pada Primigravida di Langsa, Aceh. Dari ejournal. Poltekkessmg.ac.id.

23. Yulianti. 2012. Kebidanan Oxford: Dari Bidan Untuk Bidan. Jakarta: EGC.

24. Perhimpunan Dokter Spesialis Anastesiologi dan Terapi Intensif Indonesia. 2009. PanduanTatalaksana Nyeri Operatif . Jakarta: PP IDSAI.

25. Rosalinna. 2017. Pengaruh Massage Effleurage Terhadap Pengurangan Rasa Nyeri Pada Persalinan Kala I Fase Aktif di Wilayah Kerja Puskesmas Pemalang, Surakarta, Caring, Vol.I no.2 Desember 2017 dari ejournalbina usadabali.ac.id.

26. Walyani, Purwoastuti. 2016. Asuhan Persalinan Dan Bayi Baru lahir. Yogyakarta: Pustaka Baru Press

27. Eko, Krisna dan Yetti. Penurunan Tekanan Darah Pada Klien Hipertensi Primer melalui Terapi Hipnosis. 2011 